\title{
Extensive argon laser photocoagulation in the treatment of proliferative diabetic retinopathy
}

\author{
G W AYLWARD, R V PEARSON, J D JAGgER, AND A M HAMILTON \\ From Moorfields Eye Hospital, City Road, London EC1V 2PD
}

SUMMARY A group of 20 patients (28 eyes) with proliferative retinopathy who required extensive argon laser photocoagulation to induce regression of new vessels is presented. The mean number of burns applied to each eye was 7225 , with a maximum of 11513 . These were delivered in a mean of nine sessions over a mean period of 22.9 months. Twenty-five eyes $(89 \%)$ had a final visual acuity of $6 / 18$ or better. The remaining three eyes $(11 \%)$ had severely reduced vision attributable to complications of proliferative diabetic retinopathy (traction retinal detachment involving the macula in two eyes and ischaemic maculopathy and a persistent vitreous haemorrhage in the third). Large amounts of confluent argon laser photocoagulation may be necessary for the elimination of new vessels in some patients, and it is our view that laser photocoagulation should be continued until regression of new vessels occurs. This is compatible with the retention of functional vision and good visual acuity.

Proliferative diabetic retinopathy is characterised by neovascularisation at the optic disc or in the peripheral retina. Recurrent vitreous haemorrhage and its sequelae and traction retinal detachment cause visual loss. It is the commonest cause of blindness between the ages of 30 and 65 years. ${ }^{1}$ Several controlled trials have proved the benefit of photocoagulation in the treatment of proliferative diabetic retinopathy. ${ }^{2-4}$ The largest of these was the Diabetic Retinopathy Study (DRS), which showed that a single session of photocoagulation reduced the incidence of severe visual loss (defined as a visual acuity of less than 5/200) in treated eyes. ${ }^{2}$ The beneficial effect of photocoagulation is associated with the regression of retinopathy risk factors (RRF), particularly new vessels on the disc (NVD). ${ }^{5}$ The question whether additional treatment is beneficial was not addressed by these trials, but it is widespread clinical practice to apply further laser photocoagulation until regression of new vessels occurs. How many burns can be applied? We present a group of 20 patients (28 eyes) who were included in the study because their disc new vessels required an excess of 5000 burns to induce regression, an end point which had not been achieved with lesser numbers of burns. Correspondence to Mr R V Pearson, FRCS.

\section{Patients and methods}

The appointment records of patients attending the Diabetic Clinic at Moorfields Eye Hospital were analysed with the outpatient computer. The case notes of those attending regularly for treatment over the last year were examined. Patients who had received more than 5000 argon laser burns to at least one eye were identified. Patients who had further photocoagulation pending, or who had received xenon arc photocoagulation or direct treatment to disc new vessels, were excluded from the study. Information was extracted from the notes regarding age, duration of diabetes, treatment of diabetes, visual acuity, indication for photocoagulation, presence of maculopathy and its treatment, clarity of media, number of burns, number of treatment sessions, duration of treatment (defined as the time from the first to the last treatment session), and complications of photocoagulation and proliferative diabetic retinopathy.

\section{Results}

Twenty-eight eyes in 20 patients had received more than 5000 burns. Fifteen eyes were in 10 male 
patients and 13 eyes in 10 female patients. Eight patients (five male and three female) had received more than 5000 burns in both eyes. The mean age of the patients was 36.8 years, range 19 to 71 years. The mean duration since diagnosis of diabetes in the patients was 16.7 years, range 1 to 25 years. Twentythree eyes were in 17 patients on insulin and five eyes were in three patients on oral hypoglycaemics. The indication of photocoagulation was new vessels on the disc (NVD) in all 28 eyes. Twenty eyes of 15 patients had new vessels both on the disc and elsewhere, and 17 eyes of 14 patients had some degree of vitreous haemorrhage at one or more stages before or during treatment. In all cases treatment was delivered by an argon laser through a Goldmann 3-mirror or a Rodenstock panfunduscopic contact lens. Spot size was $500 \mu \mathrm{m}$ when using the Goldmann and $200 \mu \mathrm{m}$ when using the Rodenstock contact lens with a duration of $0 \cdot 1$ to $0.2 \mathrm{~s}$. The power level was adjusted to give slight blanching of the retinal pigment epithelium. The end point of treatment was complete regression of new vessels, or complete regression of vessels with gliosis, or residual fine, flat new vessels with fibrosis which remained static for at least six months.

Data on the number of burns, number of sessions, duration of treatment, and visual acuity is shown in Table 1 . The mean total number of burns for the 28 eyes was 7255 , range 5136 to 11513 . The mean number of treatment sessions for each eye was nine, range three to 16 , and the mean duration of treatment was 22.9 months, range five to 46 months. The mean interval between sessions was 12.4 weeks. The average of the mean burns per session was 854 , range 395 to 1816 . At completion of treatment 25 eyes of 20 patients ( $89 \%$ of eyes) had a visual acuity of $6 / 18$ or better, and 16 eyes of 15 patients ( $57 \%$ of eyes) had $6 / 9$ or better. Only three eyes of three patients $(11 \%$ of eyes) had a final visual acuity of less than $6 / 18$. The visual acuities before and after treatment are represented on the scattergram in Fig. 1.

The complications of diabetic retinopathy and the degree of new vessel regression produced by photocoagulation are shown in Table 2. Ten eyes of six patients had focal (exudative) maculopathy, either before or during panretinal photocoagulation. Fourteen eyes of 10 patients had cystoid maculopathy. In five of these eyes $(1 \mathrm{R}, 1 \mathrm{~L}, 7 \mathrm{R}, 13 \mathrm{~L}$, and $18 \mathrm{~L})$ it was present before, and in the remaining nine eyes (3R, 5R, 5L, 6L, 9R, 9L, 14R, 14L, and 17R) it developed during panretinal photocoagulation. Nine of the 28 eyes received macular laser treatment. Eyes $1 \mathrm{R}$ and $1 \mathrm{~L}$ had ischaemic maculopathy. Eyes $9 \mathrm{R}$ and 9L were aphakic. Three eyes $(2 \mathrm{R}, 3 \mathrm{~L}$, and $6 \mathrm{~L})$ had rubeosis iridis, and this resolved after photocoagulation. Eye $4 \mathrm{R}$ had a superotemporal traction retinal
Table 1 Data on treatment and visual acuity

\begin{tabular}{|c|c|c|c|c|c|c|}
\hline \multirow[b]{3}{*}{ Eye } & \multirow{3}{*}{$\begin{array}{l}\text { Total } \\
\text { number of } \\
\text { burns }\end{array}$} & \multirow{3}{*}{$\begin{array}{l}\text { Number } \\
\text { of } \\
\text { sessions }\end{array}$} & \multirow{3}{*}{$\begin{array}{l}\text { Mean } \\
\text { burns per } \\
\text { session }\end{array}$} & \multirow{3}{*}{$\begin{array}{l}\text { Duration } \\
\text { of } \\
\text { treatment } \\
\text { (months) }\end{array}$} & \multicolumn{2}{|c|}{ Visual acuity } \\
\hline & & & & & Pre- & Post- \\
\hline & & & & & \multicolumn{2}{|c|}{ Treatment } \\
\hline $1 R$ & 7871 & 9 & 875 & 5 & $6 / 9$ & $6 / 18$ \\
\hline $1 \mathrm{~L}$ & 6380 & 15 & 425 & 28 & $6 / 12$ & $\mathrm{CF}$ \\
\hline $2 \mathbf{R}$ & 5332 & 9 & 592 & 34 & $6 / 6$ & $6 / 9$ \\
\hline $3 \mathbf{R}$ & 10327 & 10 & 1033 & 26 & $6 / 12$ & $6 / 12$ \\
\hline $3 \mathrm{~L}$ & 9513 & 8 & 1189 & 15 & $6 / 9$ & PL \\
\hline $4 \mathbf{R}$ & 7212 & 9 & 801 & 35 & $6 / 36$ & $6 / 6$ \\
\hline $5 \mathbf{R}$ & 5622 & 6 & 937 & 13 & $6 / 6$ & $6 / 12$ \\
\hline $5 \mathrm{~L}$ & 7558 & 8 & 945 & 13 & $6 / 5$ & $6 / 9$ \\
\hline $6 \mathrm{~L}$ & 7854 & 9 & 873 & 30 & $6 / 18$ & $6 / 12$ \\
\hline $7 \mathbf{R}$ & 7138 & 9 & 793 & 13 & $6 / 9$ & $6 / 9$ \\
\hline $8 \mathbf{R}$ & 5279 & 6 & 880 & 16 & $6 / 9$ & $6 / 9$ \\
\hline $8 \mathrm{~L}$ & 5676 & 6 & 946 & 16 & $6 / 36$ & HM \\
\hline $9 \mathbf{R}$ & 7835 & 15 & 522 & 32 & $6 / 6$ & $6 / 9$ \\
\hline 9L & 8897 & 16 & 556 & 32 & $6 / 9$ & $6 / 12$ \\
\hline $10 \mathrm{R}$ & 11513 & 13 & 886 & 35 & $6 / 9$ & $6 / 9$ \\
\hline $11 \mathrm{~L}$ & 5450 & 3 & 1816 & 5 & $6 / 5$ & $6 / 9$ \\
\hline $12 \mathrm{~L}$ & 6817 & 6 & 1136 & 21 & $6 / 5$ & $6 / 6$ \\
\hline $13 \mathbf{R}$ & 8997 & 8 & 1125 & 28 & $6 / 9$ & $6 / 6$ \\
\hline $13 \mathrm{~L}$ & 7963 & 10 & 796 & 34 & $6 / 9$ & $6 / 18$ \\
\hline $14 \mathrm{R}$ & 8705 & 10 & 870 & 32 & $6 / 9$ & $6 / 18$ \\
\hline $14 \mathrm{~L}$ & 5136 & 13 & 395 & 34 & $6 / 5$ & $6 / 9$ \\
\hline $15 \mathrm{~L}$ & 7882 & 8 & 985 & 12 & $6 / 12$ & $6 / 9$ \\
\hline $16 \mathrm{~L}$ & 5674 & 11 & 516 & 16 & $6 / 9$ & $6 / 12$ \\
\hline $17 \mathrm{R}$ & 5530 & 9 & 614 & 9 & $6 / 9$ & $6 / 9$ \\
\hline $18 \mathrm{~L}$ & 5858 & 9 & 651 & 14 & $6 / 36$ & $6 / 12$ \\
\hline 19R & 6200 & 7 & 886 & 24 & $6 / 9$ & $6 / 9$ \\
\hline 19L & 8068 & 8 & 1008 & 24 & $6 / 9$ & $6 / 9$ \\
\hline $20 \mathrm{R}$ & 6941 & 8 & 868 & 46 & $6 / 5$ & $6 / 9$ \\
\hline
\end{tabular}

detachment not involving the macula and had a final visual acuity of $6 / 6$. Of the three eyes with final visual acuities less than $6 / 18$, eyes $3 \mathrm{~L}$ and $8 \mathrm{~L}$ had a traction retinal detachment involving the macula and eye $1 \mathrm{~L}$ had ischaemic maculopathy and a persistent vitreous haemorrhage. Eyes $3 \mathrm{R}$ and $8 \mathrm{~L}$ also had persistent

\section{(Pre Rx)}

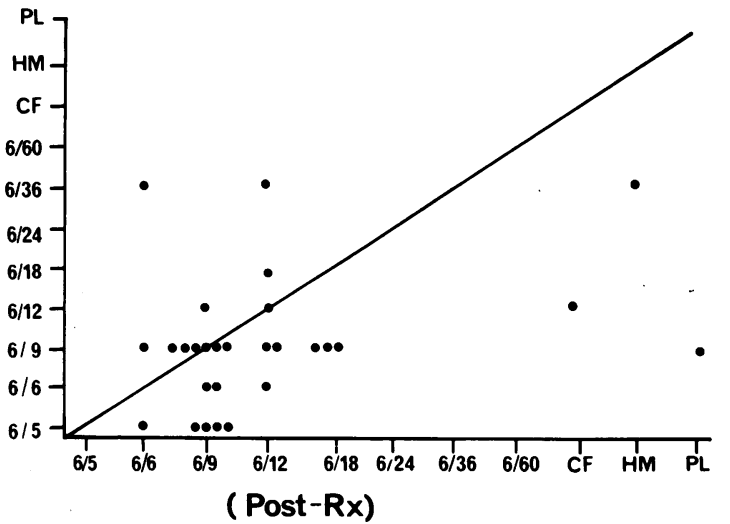

Fig. 1 Scattergram showing visual acuities before and after treatment. 
Table 2 Type of retinopathy and response to treatment

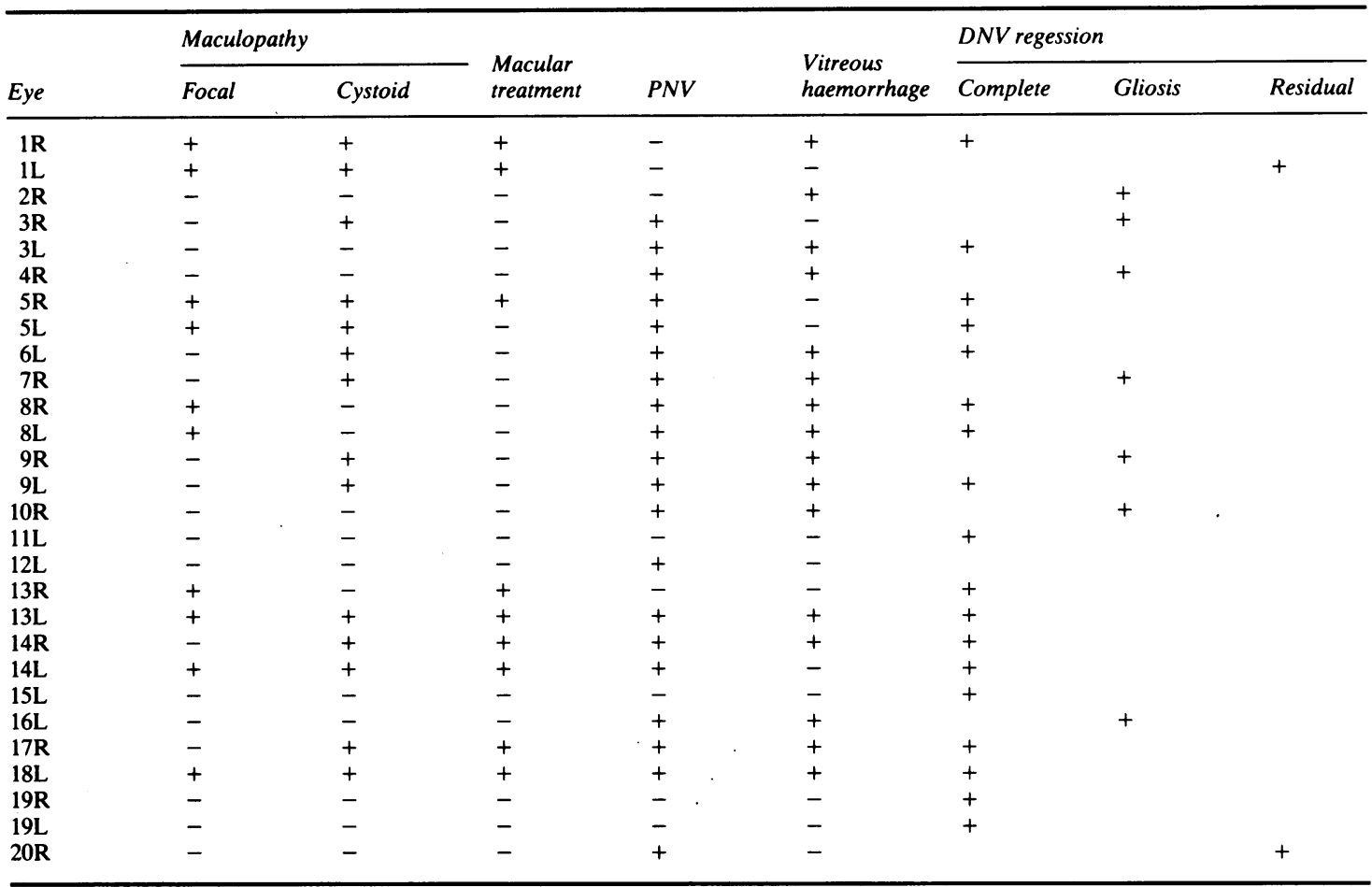

PNV: peripheral new vessels. DNV: disc new vessels. Complete: complete regression of vessels. Gliosis: complete regression of vessels with gliosis. Residual: residual fine, flat new vessels with fibrosis which remained static for at least six months.

vitreous haemorrhage. One eye had transient shallowing of the anterior chamber without angle closure following photocoagulation. There were no inadvertently placed photocoagulation burns or their associated complications.

Complete regression of disc new vessels was the end result in 18 eyes of 13 patients ( $64 \%$ of eyes). In seven eyes of seven patients ( $25 \%$ of eyes) the disc new vessels regressed completely, but varying degrees of gliosis of the optic disc remained. In three eyes of three patients ( $11 \%$ of eyes) residual, fine, flat new vessels with fibrosis, which remained static for at least six months, were present on the surface of the optic disc.

\section{Discussion}

We have presented a group of patients in whom a large amount of argon laser photocoagulation over an extended period was required in order to induce regression of new vessels. The treatment protocol for argon laser photocoagulation in the DRS specified a single session of 800 to 1600 burns of $500 \mu \mathrm{m}$ and $0 \cdot 1 \mathrm{~s}$ duration, or 500 to 1000 burns of $100 \mu \mathrm{m} .^{\circ}$ This was shown to result in a lower incidence of severe visual 
Fig. 3 Fundus photography of eye $8 R$ (5279 burns) illustrating confluent photocoagulation.

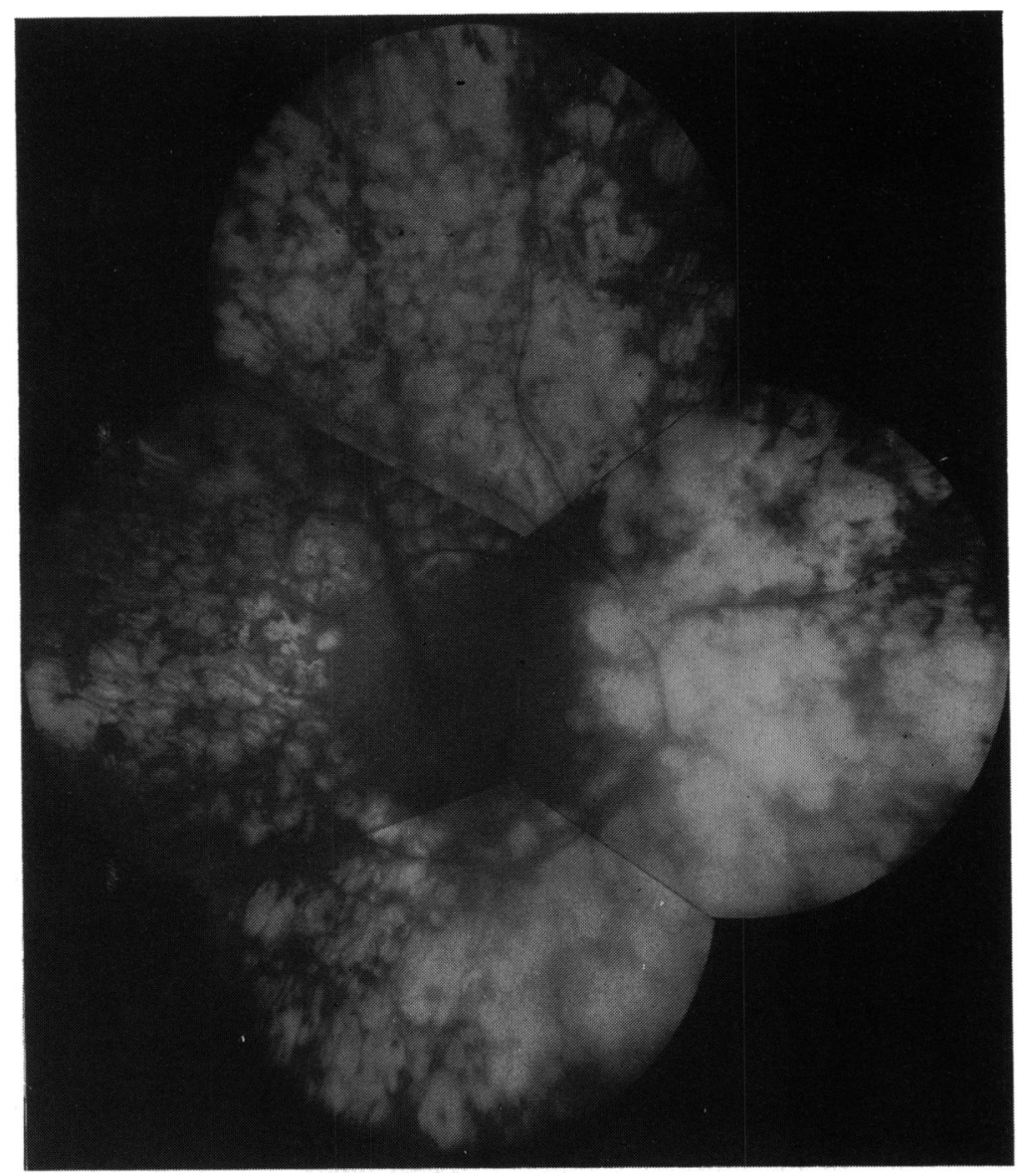

loss (less than 5/200) at two years than the untreated control group. However, many treated eyes also lost vision, and, although unproved, it seems logical to apply further treatment in an effort to eliminate new vessels. Singerman and Weaver used 2000 to 3000 burns delivered in three or four sessions in a group of juvenile onset diabetics with proliferative retinopathy. ${ }^{7}$ They concluded that the use of more extensive treatment reduced the risk of severe visual loss further than that achieved by the DRS. Little allowed supplemental treatment in a group of 351 eyes with NVD. He applied a mean of 3181 burns in several sessions with good results. Vine reviewed 23 eyes with persistent new vessels following 3000 burns and found that regression occured in 12 of these eyes after a mean of 7550 burns. $^{9}$

Given that additional panretinal photocoagulation is desirable, how should it be organised? It seems reasonable to allow time between sessions for regression to occur. In a prospective study of 50 eyes treated with a single session of 1200 argon laser burns according to the DRS protocol Doft and Blakenship found that eyes with no regression of retinopathy risk factors at 3 weeks had only a $36 \%$ chance of showing regression at 6 months. ${ }^{10}$ They achieved some degree of regression of NVD in $86 \%$ of eyes at 3 weeks and in $82 \%$ at 6 months. This suggests that a decision regarding further treatment can be made reasonably soon after the initial session. In our group of patients the mean interval between treatment sessions was 12.4 weeks, which is probably longer than necessary. It is desirable to achieve regression of blood vessels as soon as possible owing to the risk of vitreous haemorrhage which can hamper further treatment. However, this must be balanced against other factors, including the tolerance of the patient and the increased incidence of transient complications such as exudative retinal detachment, choroidal detachment, and angle closure when many burns are applied in a single session. " Of these complications we experienced only one episode of marked shallowing of the anterior chamber without angle closure. The low occurrence of these complications in our patients may be a reflection of our lack of monitoring 
in the immediate post-treatment period as well as an indication of their practical significance. Transient complications aside, Doft and Blakenship found no major differences between a single session of 1200 burns and three sessions of 400 burns in the effect of treatment on visual acuity, visual field scores, or retinopathy risk factors."

The cases we have presented represent a small minority of patients with proliferative diabetic retinopathy. However, their existence questions why some patients require such a disproportionate number of burns for regression to be induced. In Vine's study many patients had massive amounts of capillary closure on fluorescein angiography, and $50 \%$ of his patients had persistent new vessels even after an average of 7985 burns. ${ }^{9}$ Hercules et al. observed that patients with the later stages of proliferative retinopathy respond less well to panretinal photocoagulation. ${ }^{4}$

The maximum number of contiguous but nonoverlapping $500 \mu \mathrm{m}$ argon laser burns that may be applied to a retina has been estimated as $5500 .^{12}$ All but four of the eyes in this study received in excess of 5500 and one (eye $10 \mathrm{R}$ ) received more than twice this figure. There are several reasons why this should be. Firstly, the size of the histological lesion varies according to the exposure and may be smaller for lightly applied burns. ${ }^{13}$ Secondly, the edge of a previous burn as seen through the contact lens and slit-lamp may not correspond to the limit of the area of histological damage. Thirdly, a large proportion of burns were applied overlapping previous burns. This is not necessarily undesirable and indeed is essential if a confluent area of treatment is to be achieved by means of circular burns (Fig. 2). A typical example of a retina which has received such extensive treatment is shown in Fig. 3.

Other factors which could affect the number of burns required to induce regression of new vessels include the presence of opacities in the media, the degree of choroidal pigmentation, variations in the energy density at the retinal surface, ${ }^{14}$ is the operators' accommodation, the astigmatism introduced by the contact lens, and the depth of focus of the system. ${ }^{15}$

Argon laser photocoagulation is associated with several adverse effects. These may be divided into complications, such as angle closure, macular oedema, and foveal burns, and inevitable side effects such as loss of visual field and colour discrimination. ${ }^{16}$ Transient complications have already been discussed. Macular oedema occurred in nine of our patients following panretinal photocoagulation, but its development was not related to the total number of burns applied or to the mean number of burns per session, and all patients in this group had post- treatment visual acuities of $6 / 18$ or better. It is unlikely that the patients presented here will have normal visual fields or colour vision, and this will form the subject of a further study. However, it is noteworthy that despite large amounts of photocoagulation they have retained functional vision with excellent visual acuity, 25 eyes ( $89 \%$ ) having $6 / 18$ or better.

We are grateful to Max Brown, of the department of Medical Illustration, who prepared the photograph, and to the medical records staff for invaluable assistance with the retrieval of notes.

\section{References}

1 Sorsby A. Incidence and causes of blindness in England and Wales 1965-1968. London: HMSO, 1972: 10.

2 Diabetic Retinopathy Study Research Group. Preliminary report on the effects of photocoagulation therapy. $A m J$ Ophthalmol 1976; 81: 383-96.

3 Co-ordinating Committee (Hill DW, chairman). Proliferative diabetic retinopathy: Treatment with xenon-arc photocoagulation. Interim report of multicentre randomised controlled trial. Br Med J 1977; i: 739-41.

4 Hercules BL, Gayed II, Lucas SB, Jeacock J. Peripheral retinal ablation in the treatment of proliferative diabetic retinopathy. A three-year interim report of a randomised, controlled study. $\mathrm{Br} J$ Ophthalmol 1977; 61: 555-63.

5 Diabetic Retinopathy Study Research Group. Photocoagulation treatment of proliferative diabetic retinopathy. The second report of Diabetic Retinopathy Study findings. Ophthalmology 1978: 85: 82-106.

6 Diabetic Retinopathy Study Research Group. Photocoagulation treatment of proliferative diabetic retinopathy. Clinical application of Diabetic Retinopathy Study (DRS) findings, DRS report number 8. Ophthalmology 1981; 88: 583-600.

7 Singerman LJ, Weaver DT. PDR in juvenile onset diabetics: high-risk proliferative diabetic retinopathy in juvenile onset diabetics. Retina 1981; 1: 18-26.

8 Little HL. Treatment of proliferative diabetic retinopathy. Long term results of argon laser photocoagulation. Ophthalmology 1985; 92: 279-83.

9 Vine AK. The efficacy of additional argon laser photocoagulation for persistent, severe proliferative diabetic retinopathy. Ophthalmology 1985; 92: 1532-6.

10 Doft BH, Blakenship GW. Retinopathy risk factor regression after panretinal photocoagulation for proliferative diabetic retinopathy. Ophthalmology 1984; 91: 1453-7.

11 Doft BH, Blakenship GW. Single versus multiple treatment sessions of argon laser panretinal photocoagulation for proliferative diabetic retinopathy. Ophthalmology 1982; 89: 772-8.

12 Barr CC. Estimation of the maximum number of argon laser burns possible in panretinal photocoagulation. Am J Ophthalmol 1984; 97: 697-703.

13 Wallow IHL, Davis MD. Clinicopathologic correlation of xenon arc and argon laser photocoagulation. Procedure in human diabetic eyes. Arch Ophthalmol 1979; 97: 2308-15.

14 Beatrice E, Frisch G. Retinal laser damage thresholds as a function of image diameter. Arch Environ Health 1973; 27: 322.

15 Pomerantzeff O, Eng D, Schepens C. Variation of energy density in argon laser photocoagulation. Arch Ophthalmol 1975: 93: 1033.

16 Townsend, C, Hamilton AM, Cheng H. Photocoagulation in diabetic retinopathy: III. Complications. Int Ophthalmol Clin 1978; 18: $121-31$.

Accepted for publication 17 March 1988. 